\title{
Reduced antioxidant enzyme activity in brains of mice transgenic for human presenilin-1 with single or multiple mutations
}

\author{
Silke Leutner ${ }^{a}$, Christian Czech $^{b, 1}$, Katharina Schindowski ${ }^{a}$, Nathalie Touchet ${ }^{b}$, \\ Anne Eckert ${ }^{a * *}$, Walter E. Müller ${ }^{a}$ \\ 'Department of Pharmacology, Biocenter Niederursel, University of Frankfurt, Marie-Curie-Strasse 9, N 260, 60439 Frankfurt, Germany \\ 'Aventis Phama, Research and Development, Vitry-sur-Seine, France
}

\begin{abstract}
Alzheimer's disease-related mutations in the presenilin-1 gene (PS1) are leading to an elevated production of neurotoxic $\beta$-amyloid $1-42$ and may additionally enhance oxidative stress. Here, we provide in vivo evidence indicating that brains of transgenic mice expressing different human Alzheimer-linked PS1 mutations exhibit a reduced activity of two antioxidant enzymes. For this purpose, mice transgenic for human PS1 and for single and multiple PS1 mutations were generated. Mice with multiple PSI mutations showed a significantly decreased activity of the antioxidant enzymes Cu/Zn superoxide dismutase and glutathione reductase already at an age of 3-4 months. As expected, this effect was less pronounced for the mice with a single PS1 mutation. By contrast, animals bearing normal human PS1 showed sianificantly elevated enzyme activities relative to non-transgenic littermate controls. $C$-...-
\end{abstract}

Keywords. Alzheimer's disease; Reactive oxygen species; Presenilin; Superoxide dismutase; Glutathione reductase; Lipid peroxidation

Several mutations of the presenilin-I gene (PS1) are associated with early-onset familial Alzheimer's disease (FAD) (for review see [8]). The final pathogenic mechanism of PS1 mutations remains still unknown, but seems to be associated with altered proteolytic processing of the amyloid precursor protein (APP). Several findings indicate that the production of the amyloidogenic form of $\beta$-amyloid $(A \beta) \quad 1-42$ is enhanced in cells transfected with PSI mutations as well as in brains of transgenic mice expressing mutant PS1 [5]. Moreover, elevated levels of $A \beta$ were found in plasma and fibroblasts from patients with FAD-linked PS1 mutations [13].

The precise mechanisms by which these alterations lead to neurodegeneration in Alzheimer's disease (AD) are still unknown. Recent findings link the generation of reactive oxygen species (ROS) with amyloid deposition and aggregation as well as neuronal degeneration in $A D$. Synthetic $A B$ fragments can cause membrane lipid peroxidation as well as an increased production of ROS [1]. The free radical hypoth-

\footnotetext{
- Corresponding author. Tel.: +49-69-798-293-77; fax: +49-69. 79829374.

E-mail aodress: a.eckert@em.uni-frankfurt.de (A. Eckert).

1 Present address: NAP AG, Munich, Germany.
}

esis of $A B$ cytotoxicity is funther supported by the protection of neuronal cells subjected to $A \beta$ treatment by antioxidants, by inhibitors of oxidative enzyme metabolism, or by overexpression of superoxide dismutase (SOD). Moreover, recent data indicate a specific role of free radicals in the pathomechanism of human PS1 mutations. Guo et al. [9] demonstrated an increased oxyradical production, enhanced mitochondrial dysfunction and enhanced sensitivity to lipid peroxidation (LPO) in primary hippocarpal neurons from PS1 mutant knock-in mice (PSI M146V) after exposure to $A \beta$. In the present communication we describe the generation of three different types of transgenic mice expressing either a normal human PS1 transgene (PS1 wt) or a PS1 transgene bearing a single pathogenic mutation at codon MI46 (PS1 M146L) or multiple FAD-specific mutations M146L + $\mathrm{H} 163 \mathrm{R}+\mathrm{A} 246 \mathrm{E}+\mathrm{L} 286 \mathrm{~V}+\mathrm{C} 410 \mathrm{Y}$ (PS1 M5), since the combination of different PSI mutations shows additive effects on $A \beta 1-42$ secretion [4]. We further addressed the question if PS1 mutations directly alter the activity of enzymes involved in the cellular defence mechanisms for oxidative stress and whether this possible effect is more pronounced in the PSI M5 mice.

Mutagenesis of PSI was done using the SculptorTM in vitro mutagenesis system (Amersham, France). The coding 
region of PS1 was subcloned in Bluescript vector and mutations were introduced using oligonucleotides containing the desired mutation according to the protocol provided by the manufacturer.

In the first transgenic expression vector, on position 146, methionin was replaced by leucin, this mutation leads to an age of onset of 45 years in FAD patients [14]. In addition, we created a new vector combining five distinct FAD mutations (M146L + H163R + A246E + L286V + C410Y) in one expression construct (PS1 M5) [11]. The rationale behind this was to amplify eventual phenotypes in the transgenic mice due to additive effects of the different mutations, as it has been shown for the combination of two different mutations in PS1 (M146L and L286V, which are also included in the PS1 M5 mutations of the present study) with an additive effect on the A $\beta 42$ production. For the PS1 M5 construct subsequent rounds of mutagenesis were performed. All mutated sequences were verified by sequence analysis [5].

Transgene expression is under the control of the human HMG-CR-Promoter which represents a housekeeping-type promoter that shows a strong and ubiquitous expression pattern with high expression in neurons [6,7]. The method of generation and characterization of PS1 transgenic animals has been described previously [6,7]. Transgenic and nontransgenic mice were littermates or subsequent generation siblings and are therefore strain matched. PS1 transgenic mice showed normal growth and development, and revealed no apparent behavioural changes compared to littermate controls. Life duration of transgenic mice was not changed.

The comparison of mutant transgenic lines to a wild type line expressing normal human PS1 (PS1wt) suggested that mutations in PS1, and not simple overexpression of the transgene, were responsible for the cellular changes described in the following.

As already shown by other studies, transgenic mice overexpressing mutant PS1 show an elevation in A $\beta 42$, but they do not develop amyloid deposits by 24 months of age $[3,10]$. This is in contrast to APP and APP/PS1 transgenic mice [10]. Accordingly, PS1 M146L and PS1 M5 mice do not develop amyloid plaques in the brain even at the age of 13 months [11]. Therefore, it is important to investigate more subtle changes at the cellular level reported in the present study.

For Western blotting, protein extracts from brain tissue of transgenic (PS1wt, PS1 M146L and PS1 M5) or non-transgenic littermate control mice were prepared. After gel electrophoresis (SDS-PAGE), PS1 proteins were identified by immunoblotting using the antibody MAB1563 (Chemicon). Details of these assays have been described previously [7].

All mice were investigated at an age of 3-4 months and were killed by decapitation. Brains were quickly removed and tissue samples without cerebellum were homogenized. Each of the following assays was performed with every individual of each group of mice (non-transgenic mice: $n=15$; mice transgenic for human PS1wt: $n=10$; PS1
M146L mice: $n=10$; PS1 M5 mice: $n=7$ ). Superoxide dismutase (SOD) activity was measured using the SOD525 kit purchased by Calbiochem ${ }^{\circledR}$ (Bad Soden, Germany) according to the manufacturer's protocol. One SOD-525 activity unit is defined as the activity that doubles the autoxidation rate of the control blank $\left(V_{\text {sample }} / V_{\text {control }}=2\right)$. Glutathione reductase (GR) activity was assayed using a commercially available kit by Calbiochem ${ }^{\circledR}$. One GR unit is defined as the reduction of $1 \mu \mathrm{M}$ of glutathione per minute at $25^{\circ} \mathrm{C}$ and $\mathrm{pH}$ 7.6. Brain homogenates were incubated with $100 \mu \mathrm{M} \mathrm{FeCl}_{3}$ (Merck, Darmstadt, Germany) or buffer as control for $30 \mathrm{~min}$ at $37^{\circ} \mathrm{C}$. After centrifugation, the supernatants were collected and tested for lipid peroxidation (LPO) by measuring the concentration of malondialdehyde (MDA). The LPO-586 kit, purchased from Calbiochem ${ }^{\circledR}$, was used for this purpose. This kit takes advantage of a special chromogenic reagent which reacts specifically with MDA at a comparatively low temperature of incubation $\left(45^{\circ} \mathrm{C}\right)$. In order to assess whether human PS1 is expressed in the brain of the transgenic mice, we performed Western blot analysis of brain homogenates from transgenic mice and non-transgenic littermate controls. The Western blot was probed with a monoclonal antibody directed against the amino-terminal part of PS1. This antibody is specific for human PS1 since no signal of the endogenous PS1 is detectable in the homogenate of the non-transgenic mice (Fig. 1, lane 4). All three different lines of transgenic mice show clear expression of the transgene in the brain. However, the proteolytic processing of transgenic PS1 is different between constructs. The characteristic amino-terminal fragment of PS1 is detectable in the brain of mice expressing PS1 M146L and PS1 wt (Fig. 1, lane 2, 3) with the appearance of small amounts of full-length PS1 M146L most likely due to saturation of processing events as described previously in transgenic mice and rats expressing high amounts of PS1 [7,17]. However, multiple mutations in PS1 M5 resulted in a clear reduction in the N-terminal fragment and accumulation of full-length PS1 (Fig. 1, lane 1). This is most likely not due to saturation of the processing since the levels of PS1 M5 expression are lower than the

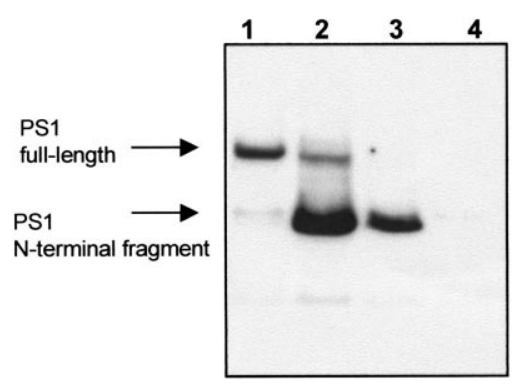

Fig. 1. Western blot analysis of PS1 expression. Expression of human PS1 is not observed in the brain of non-transgenic littermate control mice (lane 4). The amino-terminal fragment of PS1 is detectable in all groups of transgenic mice (lane $1=P S 1 \mathrm{M} 5$; lane 2 =PS1 M146L; lane $3=$ PS1wt) whereas full-length PS1 is only visible in mice expressing mutant PS1 (lane 1 and lane 2). 
levels of PS1wt or PS1 M146L protein. Instead, the accumulation of full-length protein suggests that PS1 M5 has severe structural alterations which make it no longer a substrate for the presenilinase. It was previously reported that some mutations in PS1 are able to alter the cleavage pattern towards the increase of full-length protein in transfected cells and it has been shown recently that in lymphocytes of FAD patients with PS1 mutations the PS1 proteolytic processing is impaired [16]. However, a correlation between known pathological functions of presenilin and proteolytic processing could yet not be clearly established since the naturally occurring delta-exon 9 mutation is not processed, due to the lack of the cleavage site, but still leads to an increase in A $\beta 1-42$ production [15].

Furthermore, Western-blot analysis of the different transgenic lines with a polyclonal antibody against the aminoterminus of PS1 (95/23, gift from C. Masters, Melbourne) which in addition to the transgenic human PS1 also detected the endogenous PS1 indicated that the levels of the transgenic PS1 slightly exceeded the level of endogenous murine PS1 (data not shown) [11].

To elucidate the postulated relationship between PS1 mutation and oxidative stress, we investigated SOD activity in PS1 transgenic mice. SOD is considered as a primary defence against oxidative damage rapidly converting superoxide anion to hydrogen peroxide. Cytosolic superoxide dismutase $(\mathrm{Cu}-\mathrm{Zn}$ SOD) was significantly decreased in the brains of both types of transgenic mice carrying the PS1 mutations as shown in Fig. 2A (ANOVA, $P<0.05$ ). The PS1 M146L mutation already reduced the activity of SOD by about $20 \%$ vs. PS1wt. The multiple PS1 mutations led to a further and significant decrease of the enzymatic activity of SOD (final reduction about 28\%).

In addition, we examined the activity of GR which plays an important part in the cellular antioxidant system by reducing oxidized glutathione. Again, GR was significantly

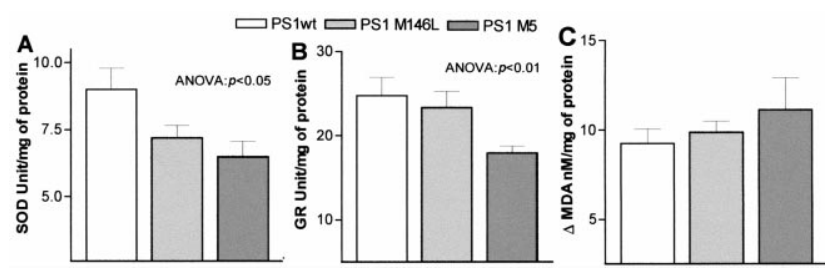

Fig. 2. Effect of human presenilin-1 (PS1) mutations on lipid peroxidation (LPO) and the antioxidant enzymes superoxide dismutase (SOD) and glutathione reductase (GR) in mouse brain. (A) Activity of the antioxidant enzyme SOD. Values represent the mean \pm SEM, $n=7-10$ animals. ANOVA indicated a significant effect over all groups $(P<0.05)$. Student's $t$-test: $P<$ 0.05 PS1wt vs. PS1 M5. (B) Activity of the antioxidant enzyme GR. Values represent the mean \pm SEM, $n=7-10$ animals. ANOVA indicated a significant effect over all groups $(P<0.01)$. Student's $t$-test: $P<0.05$ PS1 M146L vs. PS1 M5; $P=0.001$ PS1wt vs. PS1 M5. (C) Effect of iron-stimulation on lipid peroxidation, measured as an increase in the detected concentration of MDA ( $\mathrm{nM}$ of MDA per $\mathrm{mg}$ of protein). Values represent the mean \pm SEM, $n=7-11$ animals. decreased over all three groups (ANOVA, $P<0.01$ ). Mice with multiple PS1 mutations showed a significantly decreased activity (about 27\%) of the cerebral enzyme GR compared to PS1wt and to PS1 M146L mice. However, the difference in the reduction of GR activity between PS1wt mice and PS1 M146L mice was less pronounced.

Basal levels of lipid peroxidation (LPO) measured by the formation of MDA, were not significantly different among the examined groups of mice (PS1wt: $13.4 \pm 0.49$; PS1 M146L, $12.9 \pm 0.61$; PS1 M5: $13.29 \pm 0.97$; data represent concentration of MDA ( $\mathrm{nM} / \mathrm{mg}$ of protein) as means (SEM). However, PS1 mutations seem to slightly increase the sensitivity of brain cells to $\mathrm{LPO}$ after $\mathrm{FeCl}_{3}$ stimulation by $7 \%$ (PS1 M146L) or 20\% (PS1 M5) compared to PS1wt (see Fig. 2C).

The combined results of the current study obtained with three different transgenic lines are in line with findings of a completely independent study using hippocampal neurons of PS1-knock-in-mice which show increased vulnerability to lipid peroxidation when exposed to $\beta$-amyloid itself [9]. This also supports that the changes seen are resulting from expression of human PS1 and mutant PS1, suggesting that the transgenic integration site was not responsible, even if our study used only one transgenic mouse line of each transgene.

To determine whether overexpression of human PS1 links protection or vulnerability to oxidative damage, we investigated antioxidant enzyme activity and lipid peroxidation in brains of PS1wt mice and non-transgenic littermate controls. Basal levels of LPO did not differ between non-transgenic littermates and mice expressing human PS1wt. In contrast, PS1wt mice were significantly less vulnerable to LPO induced by $\mathrm{FeCl}_{3}$ than non-transgenic mice (see Table 1).

Table 1

Effect of expression of human presenilin-1 on lipid peroxidation and the antioxidant enzymes superoxide dismutase and glutathione reductase in mouse brain ${ }^{a}$

\begin{tabular}{lll}
\hline & Non-transgenic & PS1wt \\
\hline $\begin{array}{l}\text { Activity of glutathione } \\
\text { reductase }\end{array}$ & $21.36 \pm 1.24$ & $26.42 \pm 1.57^{\mathrm{b}}$ \\
$\begin{array}{l}\text { (unit/mg of protein) } \\
\text { Activity of superoxide } \\
\text { dismutase }\end{array}$ & $6.68 \pm 0.4$ & $8.99 \pm 0.78^{\mathrm{c}}$ \\
$\begin{array}{l}\text { (unit/mg of protein) } \\
\text { Iron-stimulated lipid } \\
\text { peroxidation } \\
\text { ( } \Delta \text { MDA nM/mg of protein) }\end{array}$ & $13.37 \pm 0.95$ & $9.23 \pm 0.81^{\mathrm{d}}$ \\
\hline
\end{tabular}

${ }^{a}$ Data represent the effect of iron-stimulation on LPO measured as $\Delta$ increase in the detected concentration of MDA above basal levels. Statistical analysis was performed by Student's $t$-test for independent samples.

b $P<0.05$ compared with value for non-transgenic littermate control. Values represent the mean \pm SEM, $n=7-15$ animals.

${ }^{c} P<0.01$ compared with value for non-transgenic littermate control. Values represent the mean \pm SEM, $n=10-15$ animals.

d $P<0.01$ compared with value for non-transgenic littermate control. Values represent the mean \pm SEM, $n=11-15$ animals. 
Moreover, the activities of the antioxidant enzymes GR and SOD were significantly enhanced (see Table 1). The detailed role of human PS1 in neurons is still unknown, but there is some evidence that indicates a protective role for this protein. Roperch et al. [12] described enhanced levels of apoptosis as a result of downregulation of PS1 in transfected cells. In fact, overexpression of PS1 even protects cortical neurons from experimentally induced apoptosis [2]. Thus, our data support a protective effect of human PS1 and suggest a possible role in the regulation of antioxidative defence mechanisms.

To our knowledge, this is the first study showing in vivo changes of antioxidant enzyme activities in brains from transgenic mice bearing single or multiple PS1 mutations. Consistent with the rationale that different PS1 mutations within the same molecule cause more dysfunction and higher A $\beta 1-42$ elevation than one alone [4], we found a stronger impairment of antioxidant defence mechanisms in PS1 M5 than in PS1 M146L mice. Although the mechanism by which mutated PS1 exerts these effects require further studies, our data indicate an important defect induced by PS1 mutations, which very likely contributes to the enhanced vulnerability for neurodegeneration.

The authors like to thank Drs L. Pradier, G. Tremp and P. Gallix and his team. We appreciate excellent technical assistance by J. LeGuern, G. Ret, B. Schombert, and N. Clavel. This work was supported by grants from Fonds der Chemischen Industrie and from the Dr Robert Pfleger Stiftung.

[1] Behl, C., Davis, J.B., Lesley, R. and Schubert, D., Hydrogen peroxide mediates amyloid beta protein toxicity, Cell, 77 (1994) 817-827.

[2] Bursztajn, S., DeSouza, R., McPhie, D.L., Berman, S.A., Shioi, J., Robakis, N.K. and Neve, R.L., Overexpression in neurons of human presenilin-1 or a presenilin-1 familial Alzheimer disease mutant does not enhance apoptosis, J. Neurosci., 18 (1998) 9790-9799.

[3] Chui, D.H., Tanahashi, H., Ozawa, K., Ikeda, S., Checler, F., Ueda, O., Suzuki, H., Araki, W., Inoue, H., Shirotani, K., Takahashi, K., Gallyas, F. and Tabira, T., Transgenic mice with Alzheimer presenilin 1 mutations show accelerated neurodegeneration without amyloid plaque formation, Natl. Med., 5 (1999) 560-564.

[4] Citron, M., Eckman, C.B., Diehl, T.S., Corcoran, C., Ostaszewski, B.L., Xia, W., Levesque, G., St.George, H., Younkin, S.G. and Selkoe, D.J., Additive effects of PS1 and APP mutations on secretion of the 42- residue amyloid beta-protein, Neurobiol. Dis., 5 (1998) 107-116.

[5] Citron, M., Westaway, D., Xia, W., Carlson, G., Diehl, T., Levesque, G., Johnson-Wood, K., Lee, M., Seubert, P., Davis, A., Kholodenko, D., Motter, R., Sherrington, R., Perry, B., Yao, H., Strome, R., Lieberburg, I., Rommens, J., Kim, S., Schenk, D., Fraser, P., St. George, H. and Selkoe, D.J., Mutant presenilins of Alzheimer's disease increase production of 42- residue amyloid beta-protein in both transfected cells and transgenic mice, Nat. Med., 3 (1997) 6772.

[6] Czech, C., Delaere, P., Macq, A.F., Reibaud, M., Dreisler, S., Touchet, N., Schombert, B., Mazadier, M., Mercken, L., Theisen, M., Pradier, L., Octave, J.N., Beyreuther, K. and
Tremp, G., Proteolytical processing of mutated human amyloid precursor protein in transgenic mice, Brain Res. Mol. Brain Res., 47 (1997) 108-116.

[7] Czech, C., Lesort, M., Tremp, G., Terro, F., Blanchard, V., Schombert, B., Carpentier, N., Dreisler, S., Bonici, B., Takashima, A., Moussaoui, S., Hugon, J. and Pradier, L., Characterization of human presenilin 1 transgenic rats: increased sensitivity to apoptosis in primary neuronal cultures, Neuroscience, 87 (1998) 325-336.

[8] Czech, C., Tremp, G. and Pradier, L., Presenilins and Alzheimer's disease: biological functions and pathogenic mechanisms, Prog. Neurobiol., 60 (2000) 363-384.

[9] Guo, O., Sebastian, L., Sopher, B.L., Miller, M.W., Ware, C.B., Martin, G.M. and Mattson, M.P., Increased vulnerability of hippocampal neurons from presenilin-1 mutant knock-in mice to amyloid beta-peptide toxicity: central roles of superoxide production and caspase activation, J. Neurochem., 72 (1999) 1019-1029.

[10] Holcomb, L., Gordon, M.N., McGowan, E., Yu, X., Benkovic, S., Jantzen, P., Wright, K., Saad, I., Mueller, R., Morgan, D., Sanders, S., Zehr, C., O'Campo, K., Hardy, J., Prada, C.M., Eckman, C., Younkin, S., Hsiao, K. and Duff, K., Accelerated Alzheimer-type phenotype in transgenic mice carrying both mutant amyloid precursor protein and presenilin 1 transgenes, Nat. Med., 4 (1998) 97-100.

[11] Moussaoui, S., Blanchard, V., Bonici, B., Czech, C., Tremp, G., Touchet, N., Pradier, L. and Imperato, A., Progression of neuropathology in several transgenic mice expressing a single gene or two genes linked to familial Alzheimer's disease: APP, PS-1 or both proteins, Soc. Neurosci., 25 (1999) 426.

[12] Roperch, J.P., Alvaro, V., Prieur, S., Tuynder, M., Nemani, M., Lethrosne, F., Piouffre, L., Gendron, M.C., Israeli, D., Dausset, J., Oren, M., Amson, R. and Telerman, A., Inhibition of presenilin 1 expression is promoted by p53 and p21WAF-1 and results in apoptosis and tumor suppression, Nat. Med., 4 (1998) 835-838.

[13] Scheuner, D., Eckman, C., Jensen, M., Song, X., Citron, M., Suzuki, N., Bird, T.D., Hardy, J., Hutton, M., Kukull, W., Larson, E., Levy-Lahad, E., Viitanen, M., Peskind, E., Poorkaj, P., Schellenberg, G., Tanzi, R., Wasco, W., Lannfelt, L., Selkoe, D. and Younkin, S., Secreted amyloid beta-protein similar to that in the senile plaques of Alzheimer's disease is increased in vivo by the presenilin 1 and 2 and APP mutations linked to familial Alzheimer's disease, Nat. Med., 2 (1996) 864-870.

[14] Sherrington, R., Rogaev, E.I., Liang, Y., Rogaeva, E.A., Levesque, G., Ikeda, M., Chi, H., Lin, C., Li, G. and Holman, $\mathrm{K}$. , Cloning of a gene bearing missense mutations in earlyonset familial Alzheimer's disease, Nature, 375 (1995) 754760.

[15] Steiner, H., Romig, H., Grim, M.G., Philipp, U., Pesold, B., Citron, M., Baumeister, R. and Haass, C., The biological and pathological function of the presenilin-1 Deltaexon 9 mutation is independent of its defect to undergo proteolytic processing, J. Biol. Chem., 274 (1999) 7615-7618.

[16] Takahashi, H., Mercken, M., Honda, T., Saito, Y., Murayama, M., Song, S. and Takashima, A., Impaired proteolytic processing of presenilin-1 in chromosome 14linked familial Alzheimer's disease patient lymphocytes, Neurosci. Lett., 260 (1999) 121-124.

[17] Thinakaran, G., Borchelt, D.R., Lee, M.K., Slunt, H.H., Spitzer, L., Kim, G., Ratovitsky, T., Davenport, F., Nordstedt, C., Seeger, M., Hardy, J., Levey, A.I., Gandy, S.E., Jenkins, N.A., Copeland, N.G., Price, D.L. and Sisodia, S.S., Endoproteolysis of presenilin 1 and accumulation of processed derivatives in vivo, Neuron, 17 (1996) 181-190. 